\section{$008-009$ \\ Noticias y comentarios \\ PH50 - Octubre 2004}

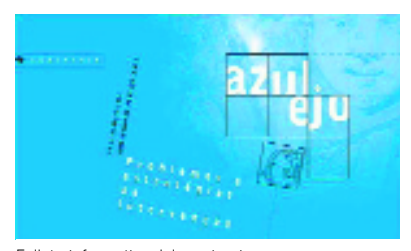

Folleto informativo del seminario

\title{
Expertos reunidos en Oporto reivindican más investigaciones sobre azulejería antigua e industrial
}

El pasado mes de mayo tuvo lugar en la ciudad de Oporto, entre los dias 20 y 22, el Seminario sobre el tema: Azulejo: problemas y estrategias de intervención organizado por el Centro de Conservação e Restauro de la Universidade Portucalense.

Los objetivos que se pretendian cubrir fueron los siguientes:

$>$ Contribuir a la sensibilización del estado del patrimonio azulejero en Portugal, aún mal estudiado y poco conservado.

$>$ Reunir de modo interdisciplinar a los profesionales que se congregan en torno a la intervenciones de conservación y restauración, como son arquitectos, ingenieros, conservadores-restauradores, responsables de empresas de restauración, historiadores del arte, investigadores de diversas instituciones y estudiantes.

> Facilitar el intercambio de experiencias entre profesionales nacionales y extranjeros.

$>$ Fomentar la creación de grupos de estudio del patrimonio azulejero portugués, dentro del período cronológico comprendido entre los siglos XV a XX.

El Seminario fue patrocinado por RECER, el mayor fabricante portugués de la industria cerámica, que presentó un taller de trabajo sobre propuestas de nuevos materiales cerámicos, destinados a la rehabilitación de espacios interiores. La realización de este taller se justificaba por la importancia que asume la aplicación de nuevos materiales al campo de la rehabilitación, siendo fundamental fomentar el diálogo entre fabricantes y responsables de proyectos patrimoniales.

El primer día estuvo dedicado a las instituciones estatales que tutelan el patrimonio inmueble donde el azulejo aparece integrado, sin olvidar la tutela privada de la Iglesia Católica. Paulo Henriques del Museu Nacional do Azulejo (MNA), con el fin de destacar la peculiaridad del uso del azulejo en Portugal, Ilamó la atención sobre la especificidad de las intervenciones en patrimonio azulejero, refiriéndose al estatuto profesional del restaurador de azulejo y al papel de consultoría que el MNA ofrece, haciendo hincapié en la preservación de la dimensión inmueble del azulejo, a través de su integración en la arquitectura. Por otro lado, y reforzando también esta idea, Adriana Ferreira do Amaral (I.P.P.A.R / I.P.P.A.A.) y Gabriel Andrade e Silva (D.R.E.M.N.), fueron unánimes en la defensa de que tanto para el I.P.P.A.R. como para la D.G.M.E.N. (Direcção-Geral dos Edifícios e Monumentos Nacionais), el azulejo dejó definitivamente de ser entendido como un elemento aislado, pasando a ser integrado en los proyectos de rehabilitación arquitectónica. Fueron analizados los casos concretos de la Capela das Almas (Porto), Claustros de Pombeiro (Felgueiras) y S.
Martinho de Tibães (Braga). La relevancia de la obra de S. Martinho de Tibães justificó la presencia de la empresa A Ludgero \& Castro, responsable de la intervención.

Constituyendo el patrimonio sacro una relevante fuente de trabajo para las empresas de restauración, se contó también con la presencia del Obispo de Coimbra, en calidad de presidente de la Comissão dos Bens Culturais da Igreja y de José Manuel Ribeiro por la Comissão de Arte Sacra do Norte. Fueron abordados los modus operandi de la Iglesia en su relación con los fieles, comisiones de las fábricas de las iglesias y empresas de restauración, así como el azulejo como arte decorativa al servicio de la liturgia y la urgencia en la recuperación de esa memoria.

Otra gran sección de este seminario estuvo dedicada a los investigadores. Destacamos las comunicaciones de Rosário Veiga (L.N.E.C.) sobre argamasas de revestimiento en paredes antiguas, de João Coroado (I.P.T./C.T.C.V.) sobre composición y propiedades de los azulejos del siglo XVIII, de João Luis Antunes (I.P.T.) relativa a las anomalias más frecuentes en paneles azulejeros, y de Ana Ferreira (Signinum - Gestão do Património Cultural), que analizó la aplicación concreta de los métodos de diagnóstico para cada caso de estudio concreto. Le correspondió a Miguel Abreu (L.N.E.C.) abordar las anomalias en los revestimientos cerámicos actuales, investigación desarrollada bajo la supervisión del reconocido investigador Carvalho Lucas, recientemente fallecido, por lo que se aprovechó esta oportunidad como homenaje póstumo.

El momento más importante del encuentro vino dado por la experiencia de conservación y restauración del Taller de Empleo de la Plaza de España de Sevilla, a cargo de Moisés Moreno y Román Ginés Alfonso. La presentación de este proyecto representó, por su magnitud y metodología, la comunicación más participativa.

De la realización de este seminario resultaron como conclusiones destacables:

$>$ La necesidad de organizar un Seminario anual dedicado a los problemas del azulejo.

> La conveniencia de impulsar grupos de estudio especificos sobre azulejería antigua e industrial.

> La urgencia de promover la elaboración de proyectos de investigación sobre azulejería, en especial a nivel de máster y de doctorado.

Eduarda Moreira da Silva

Coordinadora del Centro de Conservación y

Restauración de la Universidade Portucalense 